\title{
Influence of Ball Screw Equipped with Counter-balance Mechanism on Machine Tool Vibration in Step-drilling Process
}

\author{
Ryosuke SHIBATA $^{1, *}$, Toshiki HIROGAKI ${ }^{1}$, Eiichi AOYAMA ${ }^{1}$, Keiji OGAWA $^{2}$, Tatsuya YAMASHITA ${ }^{1}$ \\ ${ }^{1}$ Faculty of Science and Engineering, Doshisha University, Japan \\ ${ }^{2}$ Faculty of Science and Technology, Ryukoku University, Japan
}

Copyright $(2015$ by authors, all rights reserved. Authors agree that this article remains permanently open access under the terms of the Creative Commons Attribution License 4.0 International License

\begin{abstract}
There has recently been an increasing demand for miniaturization and multi-functionalization of electronic equipment due to developments in information technology (IT). The semiconductor package printed wiring boards (PWBs) used in the central processing units (CPUs) of various electronic devices have brought about many advanced features. While the micromachining of Si wafers and integrated circuits has improved, advanced processing technologies for micro-drilling in PWBs are also required. Consequently, demands have been made to miniaturize PWBs and fabricate highly dense electrical circuit layers. To make these demands a reality, it has been necessary to decrease the diameter and distance between the wall surfaces of through holes. However, problems have emerged in that the drilling tools bend and break during the drilling process, and heat occurs damage around the drilled holes after the drilling process due to the increased drilling aspect ratio between the depths and diameters of holes. Method of step-feed drilling are generally considered to be effective ways of solving these problems. However, alternation short stroke motions by the spindle axis are needed to do the step-drilling process and these motions cause various kinds of vibrations. A machine tool was constructed with a novel counter-balance mechanism on the spindle driving Z-axis and investigated a model to estimate the appropriate balance mass for the step-drilling process. The results were compared from the frequency responses of the proposed model with these from experiment, and found that vibration could be controlled with the counter-balance mechanism. The results demonstrated that the proposed vibration-proof method could reduce vibration in high-speed step-micro-drilling motions and to improve quality of the drilled holes and the efficiency of the micro-drilling process in PWB manufacturing fields.
\end{abstract}

Keywords Machine Tool, Micro Drill, Printed Wiring Boards, Step Cycle, High Speed Spindle, Counter-balance, Vibration, Modeling

\section{Introduction}

The semiconductor package printed wiring boards (PWBs) used in the central processing units (CPUs) that are used in various electronic devices have modeled advanced features. While micromachining of Si wafers and integrated circuits has improved, advanced processing technology for micro-drilling in PWBs is still required. Drilling using micro-drills of $0.2 \mathrm{~mm}$ or less in diameter and a super-high-speed spindle of $160,000 \mathrm{rpm}$ or more has been developed[1][2]. Micro-hole drilling of PWBs is currently often done with non-step drilling with straight drills. This is because drilling in several steps cannot achieve high productivity or attain complicated combinations of number of steps, feed speeds, or strokes in each step. However, non-step drilling causes heat damage called B-rings on PWBs because they are heated higher than the glass-transition point due to friction[3]. The through holes of PWBs need to be ever smaller, on the other hand, so step-feed drilling, which is a method of drilling through holes using several cutting feeds, is one of the most efficient methods of preventing the micro-drills from breaking[4].

The balance mass was tuned up to adapt several-step drilling processes that could prevent micro-drills from breaking in a machine tool equipped with a counter-balance mechanism on the Z-axis that moved the spindle. We compared a frequency response that was determined by a model of the mechanism with the experimental results, and investigated control of the vibration effects with a counter-balance mechanism. We investigated the effect on vibration characteristics and the method of setting the counter mass by changing it.

\section{Experimental Set Up}

We used the teststand for a ball screw(KR30H10, THK Co., Ltd.) in the experiment, which we used for a model with a $\mathrm{CNC}$ high-speed one-spindle hole drilling machine 
(ND-122L, Takeuchi Co., Ltd.) (Fig. 1). The teststand for the ball screw is shown in Fig. 2. The main characteristic of this machine tool is that it was equipped with a counter balance mechanism. A counter was tandemly connected to the spindle with a backward screw, as shown in Fig. 1. It effectively reduced vibration by balancing the translation axis in the Z-direction with a counterbalance and the spindle moved in reverse when it moved up and down. We investigated the influence of all the parameters of the ball screw of the machine tool that became complicated using the teststand. The teststand was operated with a horizontal setting to avoid complex phenomena and to confirm the model was precise. The teststand has a ball screw $10.0 \mathrm{~mm}$ in diameter, all its strokes were $200.0 \mathrm{~mm}$, and its movement stroke was $151.0 \mathrm{~mm}$. In addition, the weight of the spindle was $2.0 \mathrm{~kg}$, and the counterweight became a structure that could change from $0.3 \mathrm{~kg}$ to $\sim 2.8 \mathrm{~kg}$, as shown in Fig. 3. Fig. 4 shows the processing movements that we used in the experiment. The rate of movement of the fast feed was 500 $\mathrm{mm} / \mathrm{s}$ and that of the constant feed was $140 \mathrm{~mm} / \mathrm{s}$ during processing. We used a rapid feed step cycle in the non-drilling section when it was in step drilling in three steps. This is because it effectively improved the quality of the holes by allowing each step to play a role in prepared hole and in main and finishing process. In addition, the feed rate each step used was divided into movement strokes in three parts. Fast feed and constant feed ware determined three times in non-step movements to maintain processing efficiency.

The positions at which acceleration was measured are shown in Fig. 2.

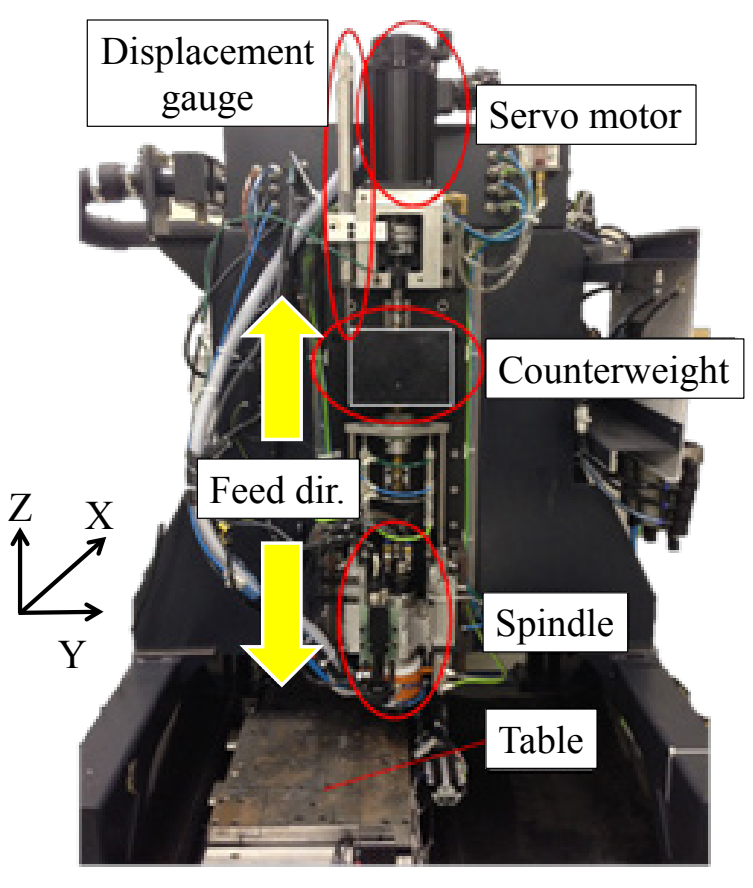

(a) Counterbalance system

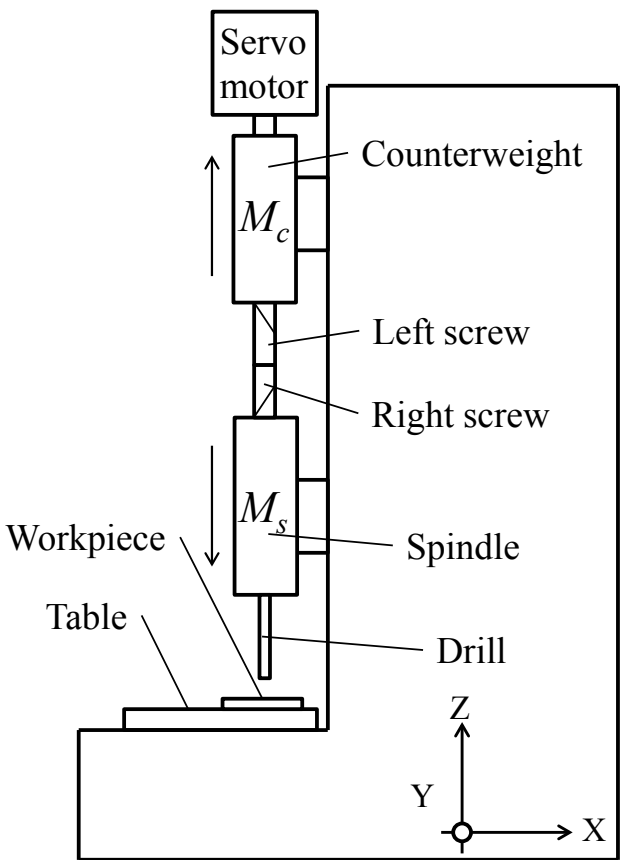

(b) Schematic of machine tool

Figure 1. Machine tool equipped with counter-balance mechanism 


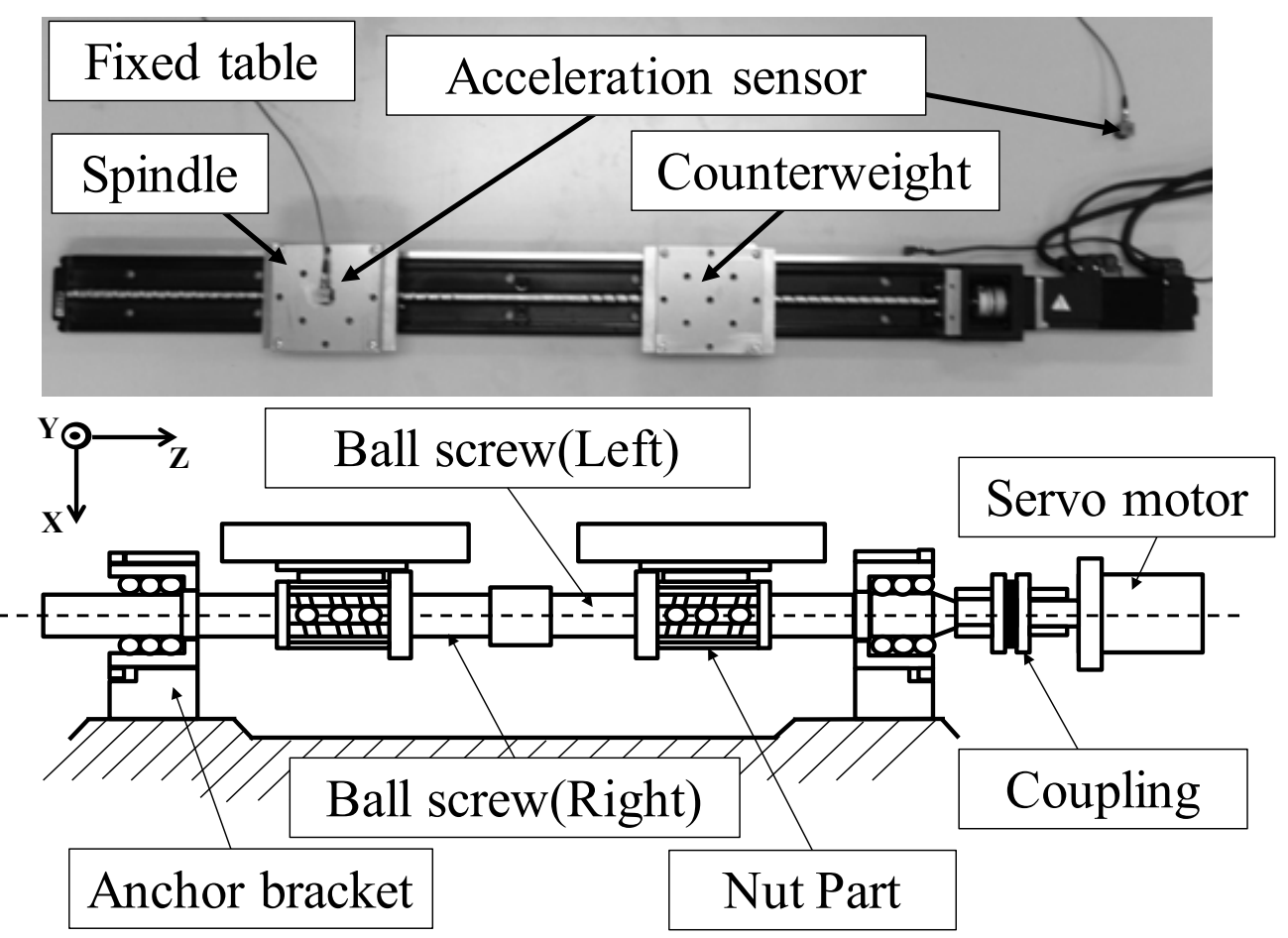

Figure 2. Teststand for ball screw transport

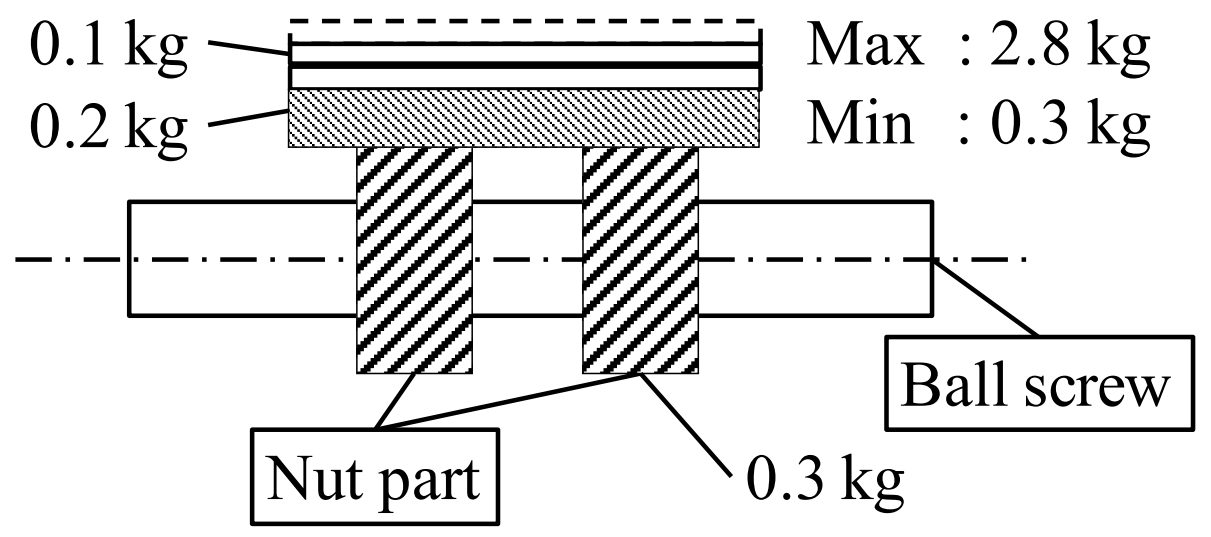

Figure 3. Structure of counterweight

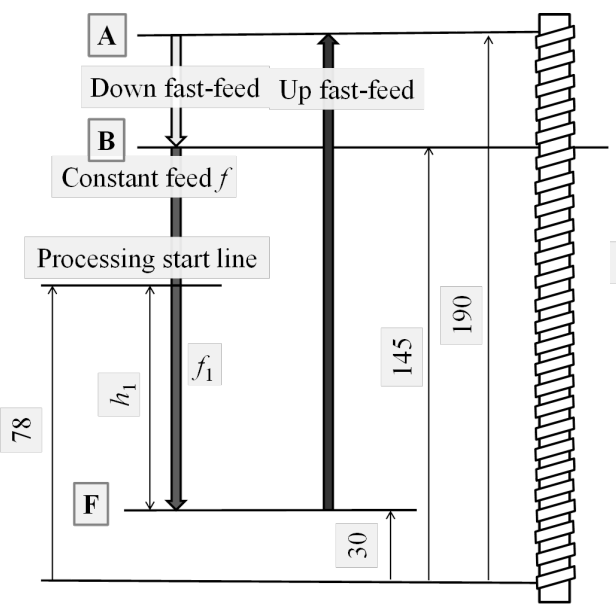

(a) Non-step drilling

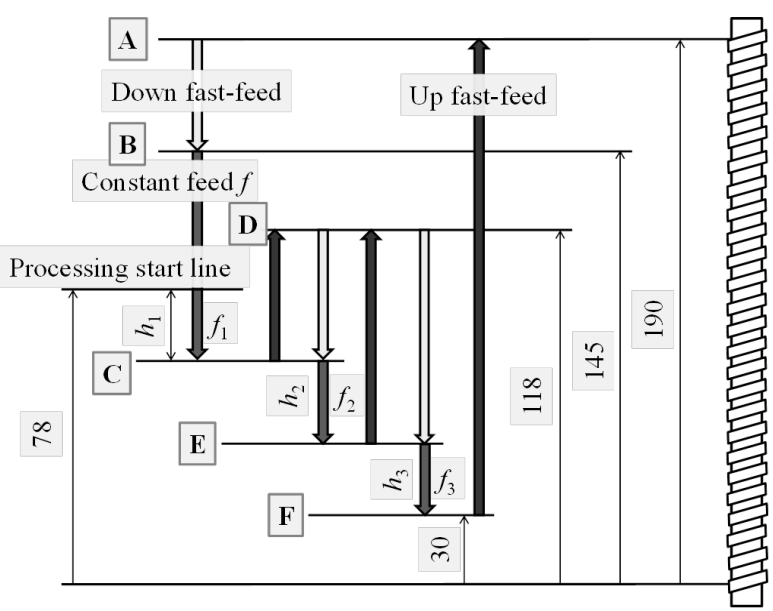

(b)Three-step drilling

Figure 4. Step cycles during one-hole drilling 


\section{Model Diagram}

Four inertia models [5] of the ball screw were tandemly connected in this machine tool and were used for modeling. The model diagram generally used two inertia models. However, we created a model diagram by taking into consideration the torsion rigidity of the ball screw and the viscous coefficient of friction of the linear guide because the motion of the machine tool was insignificant. The support form on the motor side and on the anti-motor side consisted of a structure called a single anchor which is fixed-support. The support form on the spindle side was only to restrict only the radial direction on the spindle side. Fig. 5 outlines the dynamics model that was considered. This model diagram shows seven inertia models and has seven degree of freedom $\left(\theta_{m}, \theta_{b r}, \theta_{b l} Z_{b r}, Z_{b l}, Z_{c} Z_{s}\right)$. The counter-balance mechanism is the most important. This is because the relation of the weight of the spindle and the counterbalance affected vibration in the work space. Therefore, we defined $\alpha=\mathrm{Mc} / \mathrm{Ms}$ as the weight ratio and investigated the weight ratio and what influence it had on vibration. The values of the parameters we used in the model are summarized in Table 1.

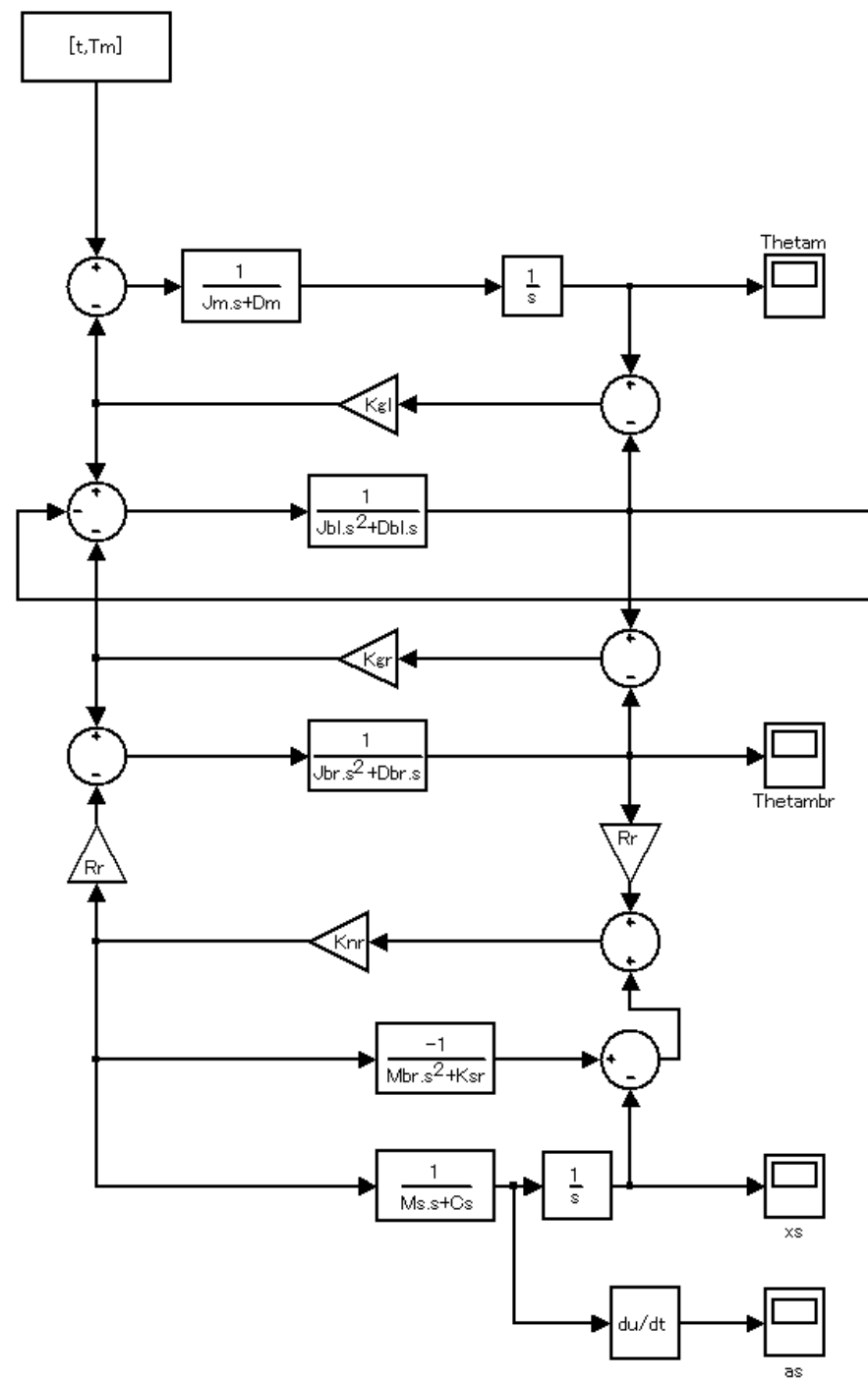

Figure 6. Block diagram of mechanical model

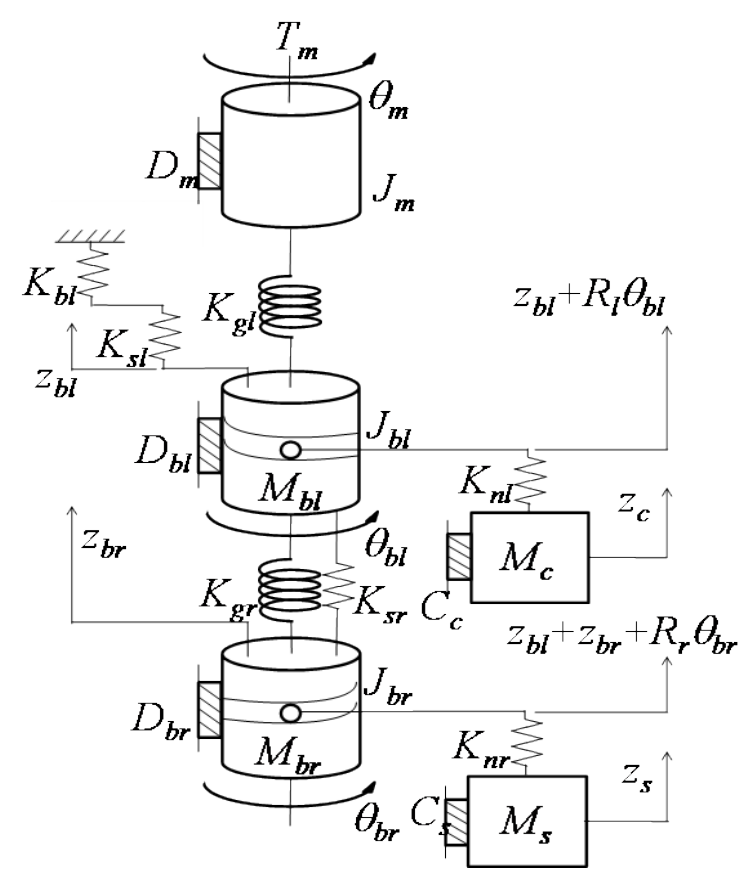

Figure 5. Mechanical model

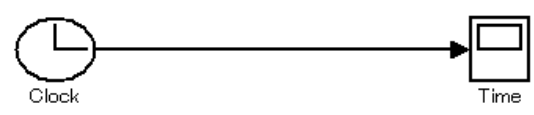


Table 1. Parameters of model

\begin{tabular}{|c|c|c|c|c|c|}
\hline & Parameters & $\begin{array}{l}\text { Numerical } \\
\text { value }\end{array}$ & & Parameters & Numerical value \\
\hline $\mathrm{T}_{\mathrm{m}}$ & Motor torque $[\mathrm{N} \cdot \mathrm{m}]$ & & $\mathrm{M}_{\mathrm{c}}$ & Counter weight $[\mathrm{kg}]$ & $\begin{array}{l}0.3,1.4 \\
2.0,2.8\end{array}$ \\
\hline$\theta_{\mathrm{m}}$ & Motor turn angle [rad] & & $\mathrm{M}_{\mathrm{s}}$ & Spindle weight $[\mathrm{kg}]$ & 2.0 \\
\hline$\theta_{\mathrm{br}}$ & Ball screw turn angle [rad] & & $\mathrm{M}_{\mathrm{br}}$ & Ball screw weight $[\mathrm{kg}]$ & 0.12 \\
\hline$\theta_{\mathrm{bl}}$ & $\begin{array}{l}\text { Twisted contrary ball screw turn angle } \\
{[\mathrm{rad}]}\end{array}$ & & $\mathrm{M}_{\mathrm{bl}}$ & $\begin{array}{c}\text { Twisted contrary ball screw weight } \\
{[\mathrm{kg}]}\end{array}$ & 0.12 \\
\hline$Z_{\mathrm{br}}$ & Ball screw position $[\mathrm{m}]$ & & $\mathrm{K}_{\mathrm{gr}}$ & $\begin{array}{l}\text { Torsion rigidity of ball threaded shaft } \\
{[\mathrm{N} \cdot \mathrm{m} / \mathrm{rad}]}\end{array}$ & 184 \\
\hline $\mathrm{Z}_{\mathrm{bl}}$ & $\begin{array}{c}\text { Twisted contrary ball screw position } \\
{[\mathrm{m}]}\end{array}$ & & $\mathrm{K}_{\mathrm{gl}}$ & $\begin{array}{l}\text { Torsion rigidity of twisted contrary } \\
\text { ball threaded shaft }[\mathrm{N} \cdot \mathrm{m} / \mathrm{rad}]\end{array}$ & 194 \\
\hline$Z_{c}$ & Counter position $[\mathrm{m}]$ & & $\mathrm{K}_{\mathrm{bl}}$ & $\begin{array}{l}\text { Axial rigidity of support bearing of } \\
\text { ball threaded shaft }[\mathrm{N} / \mathrm{m}]\end{array}$ & $\begin{array}{r}7.5 \\
\times 10^{8} \\
\end{array}$ \\
\hline$Z_{\mathrm{s}}$ & Spindle position [m] & & $\mathrm{K}_{\mathrm{sr}}$ & $\begin{array}{l}\text { Axial rigidity of the ball threaded shaft } \\
{[\mathrm{N} / \mathrm{m}]}\end{array}$ & $\begin{array}{r}6.0 \\
\times 10^{7} \\
\end{array}$ \\
\hline $\mathrm{J}_{\mathrm{m}}$ & $\begin{array}{l}\text { Moment of inertia of the motor }[\mathrm{kg} \cdot \\
\left.\mathrm{m}^{2}\right]\end{array}$ & $\begin{array}{r}1.0 \\
\times 10^{-5} \\
\end{array}$ & $\mathrm{~K}_{\mathrm{sl}}$ & $\begin{array}{l}\text { Axial rigidity of twisted contrary ball } \\
\text { threaded shaft }[\mathrm{N} / \mathrm{m}]\end{array}$ & $\begin{array}{c}6.3 \\
\times 10^{7} \\
\end{array}$ \\
\hline $\mathrm{J}_{\mathrm{br}}$ & $\begin{array}{c}\text { Moment of inertia of ball screw }[\mathrm{kg} \cdot \\
\left.\mathrm{m}^{2}\right]\end{array}$ & $\begin{array}{l}1.50 \\
\times 10^{-6} \\
\end{array}$ & $\mathrm{~K}_{\mathrm{nr}}$ & Axial rigidity of tnut $[\mathrm{N} / \mathrm{m}]$ & $\begin{array}{r}5.5 \\
\times 10^{7} \\
\end{array}$ \\
\hline $\mathrm{J}_{\mathrm{bl}}$ & $\begin{array}{l}\text { Moment of inertia of twisted contrary } \\
\text { ball screw }\left[\mathrm{kg} \cdot \mathrm{m}^{2}\right]\end{array}$ & $\begin{array}{l}1.50 \\
\times 10^{-6} \\
\end{array}$ & $\mathrm{~K}_{\mathrm{nl}}$ & Axial rigidity of nut [N/m] & $\begin{array}{r}5.5 \\
\times 10^{7} \\
\end{array}$ \\
\hline $\mathrm{D}_{\mathrm{m}}$ & $\begin{array}{l}\text { Viscous coefficient of friction of } \\
\text { motor axis }\left[\mathrm{kg} \cdot \mathrm{m}^{2}\right]\end{array}$ & 0.00 & $\mathrm{R}_{\mathrm{r}}$ & $\begin{array}{l}\text { Conversion coefficients from turn to } \\
\text { direct motion }[\mathrm{m} / \mathrm{rad}]\end{array}$ & \\
\hline $\mathrm{D}_{\mathrm{br}}$ & $\begin{array}{l}\text { Viscous coefficient of friction of } \\
\text { threaded shaft }\left[\mathrm{kg} \cdot \mathrm{m}^{2}\right]\end{array}$ & 0.05 & $\mathrm{R}_{1}$ & $\begin{array}{c}\text { Conversion coefficients from turn to } \\
\text { direct motion }[\mathrm{m} / \mathrm{rad}]\end{array}$ & \\
\hline $\mathrm{D}_{\mathrm{bl}}$ & $\begin{array}{l}\text { Viscous coefficient of friction of } \\
\text { threaded shaft }\left[\mathrm{kg} \cdot \mathrm{m}^{2}\right]\end{array}$ & 0.05 & $l_{p}$ & Quantity of movement per round & 0.01 \\
\hline $\mathrm{C}_{\mathrm{c}}$ & $\begin{array}{l}\text { Viscous coefficient of friction of } \\
\text { linear guide of counter }\left[\mathrm{kg} \cdot \mathrm{m}^{2}\right]\end{array}$ & $\begin{array}{l}1.0 \\
\times 10^{4} \\
\end{array}$ & $\mathrm{R}$ & $\mathrm{R}=1_{\mathrm{p}} / 2 \pi$ & \\
\hline $\mathrm{C}_{\mathrm{s}}$ & $\begin{array}{l}\text { Viscous coefficient of friction of } \\
\text { linear guide of } \quad \text { spindle }\left[\mathrm{kg} \cdot \mathrm{m}^{2}\right]\end{array}$ & $\begin{array}{l}1.0 \\
\times 10^{4} \\
\end{array}$ & & & \\
\hline
\end{tabular}

\section{Simulation}

We simulated the transmission functions from motor torque $[\mathrm{N} \cdot \mathrm{m}]$ to motor angular velocity $[\mathrm{rad} / \mathrm{m}]$ to confirm changes in the natural frequency with changes in the counterweight. We created a block diagram to simulate this, which is shown in Fig. 6, and Fig. 7 presents the results from simulation with four kinds of characteristics. The magnitude in decibels is $20 \log$ (motor-angular-velocity/motor-torque) in Fig. 7. The peak of the amplitude in the vicinity of 1000 $[\mathrm{Hz}]$ in Fig.7 is caused by axial vibration and the peak in the vicinity of $500-600[\mathrm{~Hz}]$ is due to the influence of the right ball screw where it moved to the spindle position. In contract, the peak in the vicinity of $1300[\mathrm{~Hz}]$ moved to the low frequency side along with the increasing counterweight. This peak was caused by the axial vibration of the left ball screw where it moved to a counter position. The values of the peaks of the two axial vibrations were equal especially at $\alpha=0.7$, and the amplitude was particularly reduced slightly at $\alpha=0.15$ (not equipped with counterweight). This phenomenon may be in a relation like that of dynamic dampers. The result where the peaks of axial vibration comprised and amplified vibration are presented in the case of $\alpha=1.4$ that made the counterweight heavier than the weight of the spindle. The peaks at $1700[\mathrm{~Hz}]$ and $3000[\mathrm{~Hz}]$ were caused by torsion vibration, the peak at $1700[\mathrm{~Hz}]$ may have been related to the right ball screw, and the peak at $3000[\mathrm{~Hz}]$ may have been related to the left ball screw. Torsion vibration approximately similar results except for $\alpha=0.15$. This may have been caused by huge loads imposed by the ball screw because it was equipped with a counterweight. The peak at $5000[\mathrm{~Hz}]$ may have been influenced by the nut part of the left ball screw because there were no peaks for $\alpha=0.15$. In contrast, there were no peaks due to the nut part of the right ball screw in Fig. 7. However, this frequency supposedly added to the peak at $3000[\mathrm{~Hz}]$. This is because the peak at $3000[\mathrm{~Hz}]$ that was due to the torsion vibration of the left ball screw was larger than the peak caused by the greater torsion vibration of the right ball screw.

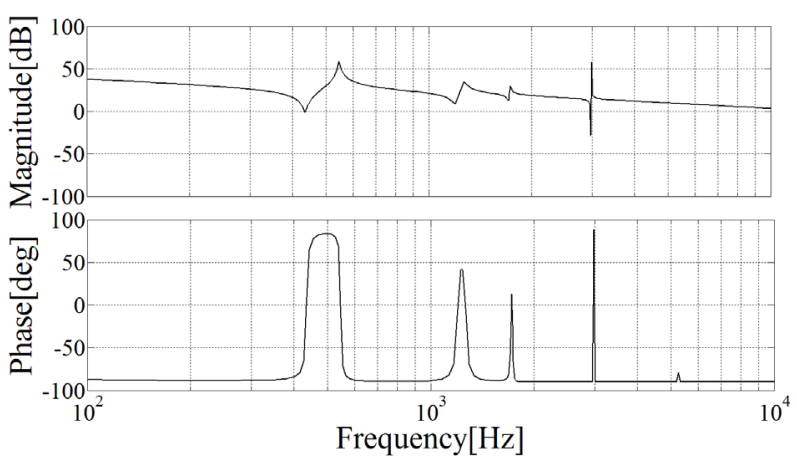

(a) $\alpha=0.15$ 


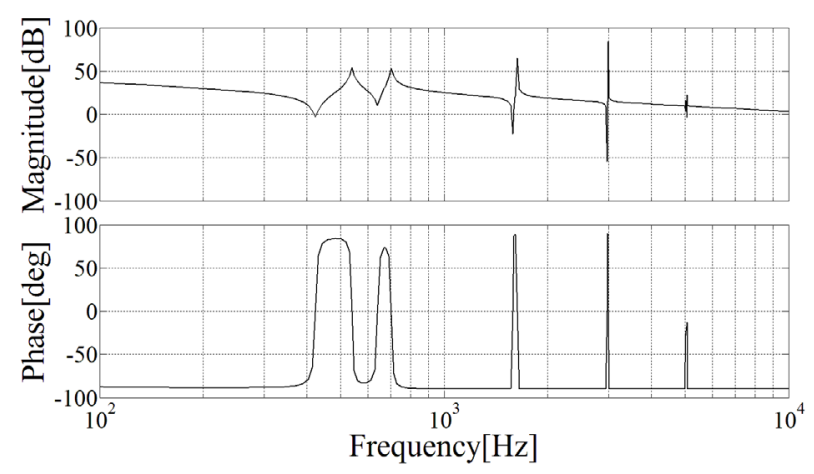

(b) $\alpha=0.7$

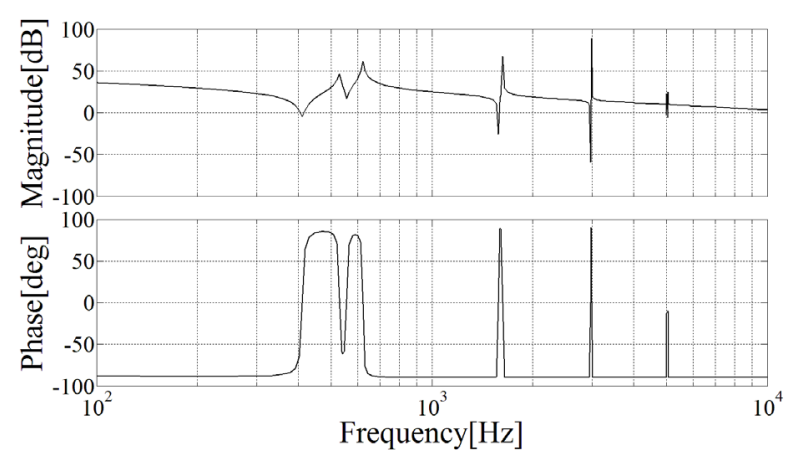

(c) $\alpha=1.0$

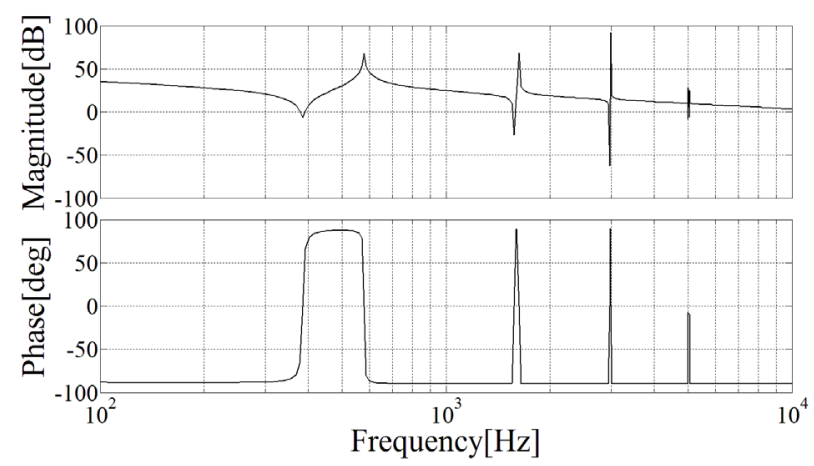

(d) $\alpha=1.4$

Figure 7. Simulation of frequency response

\section{Comparison of Experiments and Simulations}

All experiments involved Non-step drilling and Three-step drilling. It was necessary to investigate the effect of reducing vibration by balancing the translation axis of the counter balance mechanism. Therefore we measured the $\mathrm{Z}$-axis acceleration of the fixed table and investigated the acceleration spectral density (ASD). Fig. 8 plots the results where vibration in the $8[\mathrm{~Hz}]$ vicinity, which is the natural frequency of the fixed table, was largely reduced at $\alpha=1.0$ during Non-stop and three-step drilling. Therefore, we knew that the translation in the direction axis of the $\mathrm{Z}$-axis was balanced at $\alpha=1.0$.

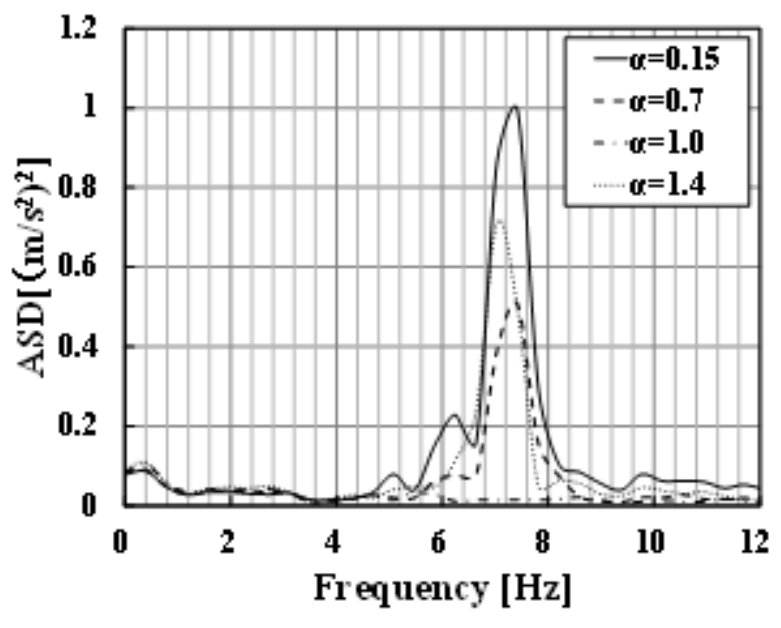

(a) Non-step drilling

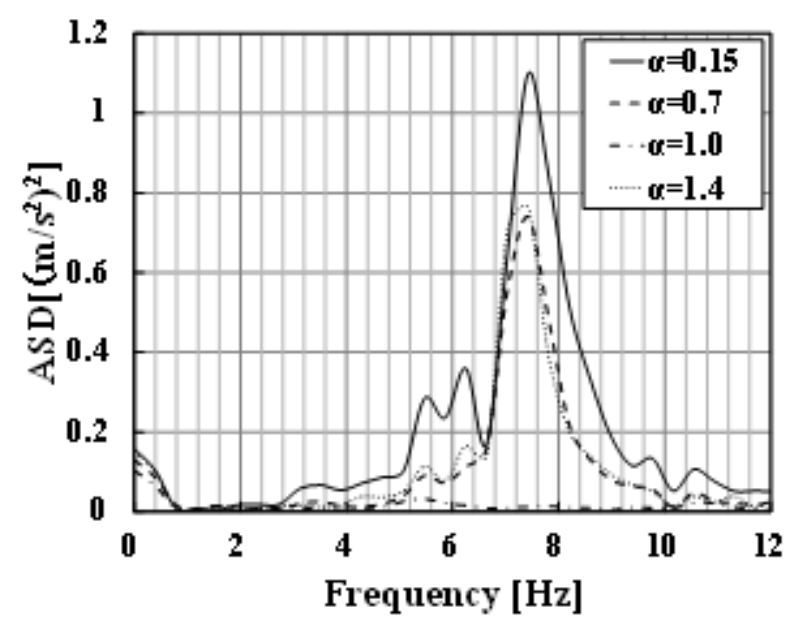

(b) Three-step drilling

Figure 8. Acceleration spectrum density of Z-axis for fixed table

We compared the natural frequency inherent in the ball screw with the simulation results. We also measured the Z-axis acceleration of the spindle and investigated the ASD. Fig 9 and Fig. 10 presents the results we obtained from the experiments. The frequency of axial vibration and torsion vibration of the ball screw indicated a value that was near that obtained from the simulation results. Furthermore, the frequency of the axial vibration of the left threaded shaft changed at low levels as the counterweight increased as it did in simulation. However, a phenomenon like that of a dynamic damper was observed at $\alpha=0.7$ in the simulation, but the phenomenon was not observed at $\alpha=1.4$ according to the actual results. The dynamic damper was expected to increase the counterweight more according to Fig. 9(d). Thus, expected that torsion vibration would increase. Therefore, it was necessary to investigate the axial and torsion vibrations of the ball screw in relation to the trade-off in detail to set the most suitable weight for the counter. 


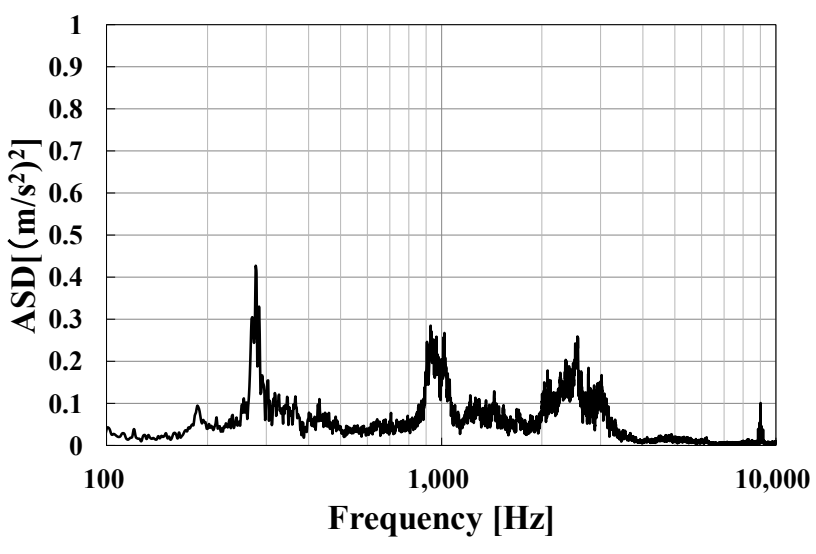

(a) $\alpha=0.15$

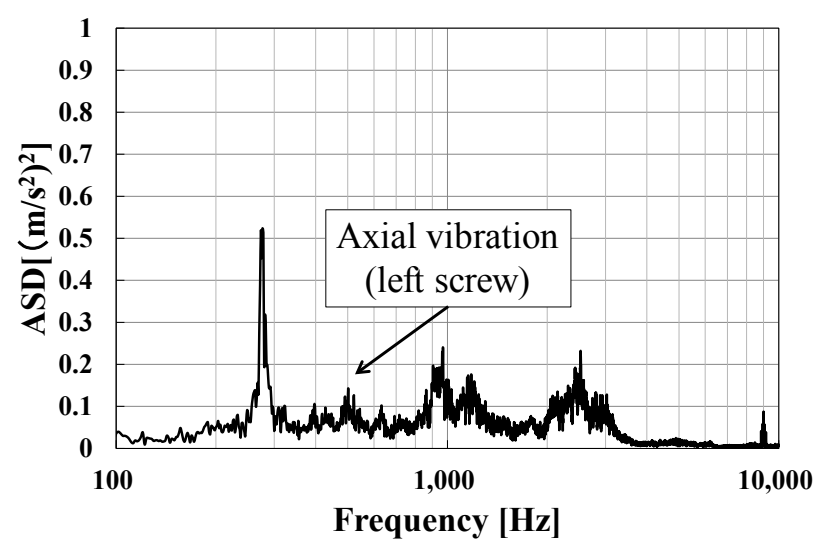

(b) $\alpha=0.7$

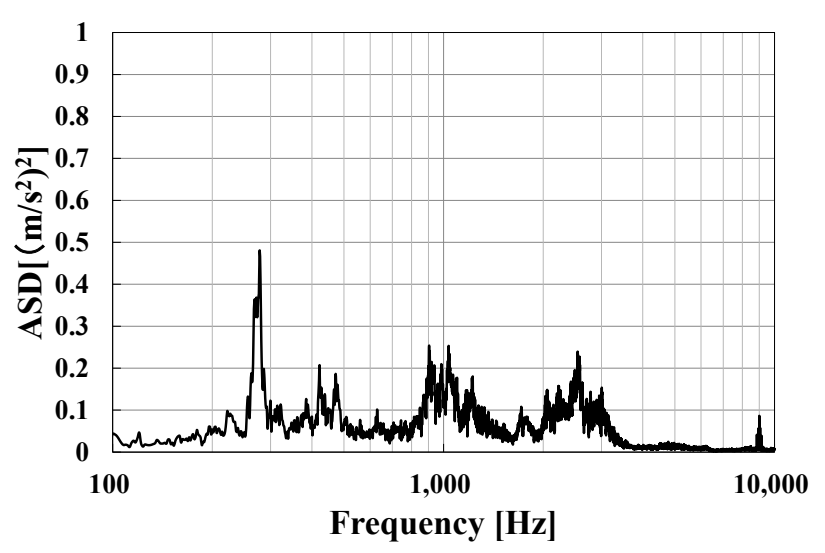

(c) $\alpha=1.0$

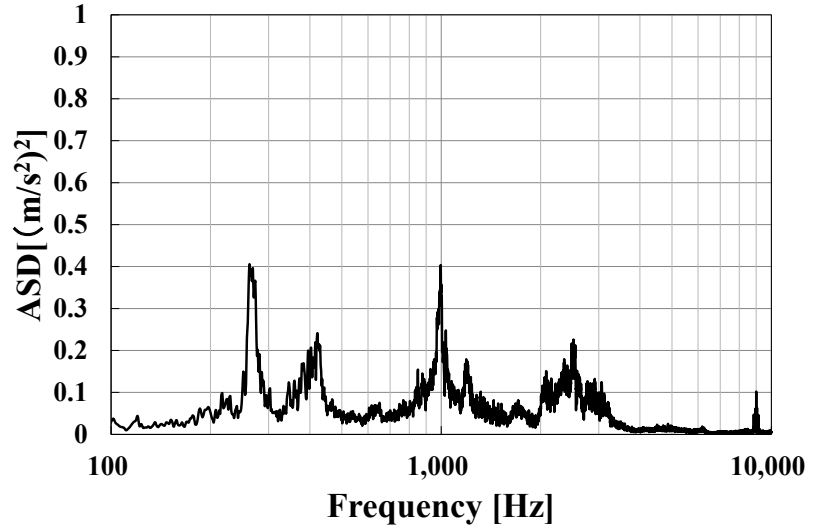

(d) $\alpha=1.4$

Figure 9. Acceleration spectrum density of Z-axis of spindle

The peak of the frequency in Three-step drilling became a value that was near that in simulation like that in non-step drilling. However, the axial vibration increased with increased counterweight, and the torsion vibration decreased in contrast that in Non-step drilling. Furthermore, results like those for the dynamic damper were obtained at $\alpha=1.0$. Therefore, it was necessary to change the parameters by using frequencies that needed to be decreased. This was because there was a trade-off in the amplitudes of frequencies. Furthermore, it was necessary to consider the influence of movement, because the natural frequency of the ball screw transport was changed by the pattern of movements.

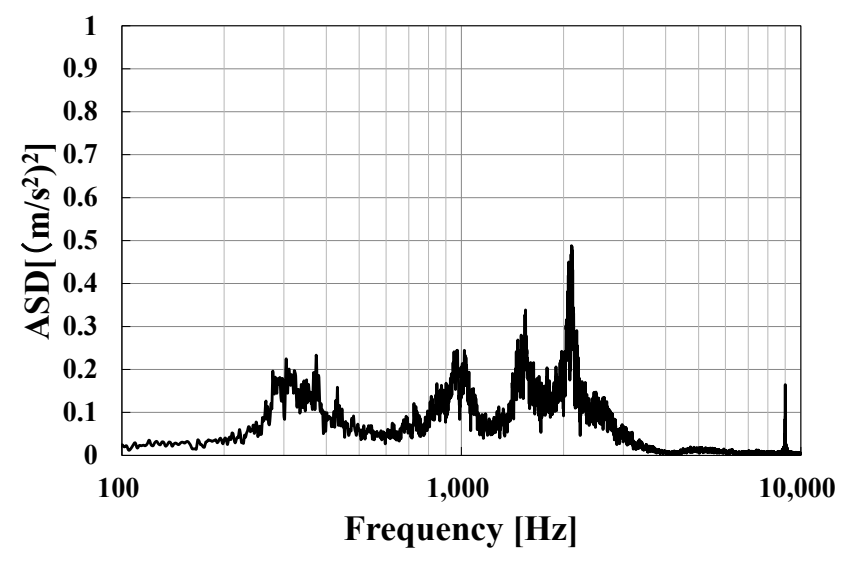

(a) $\alpha=0.15$ 


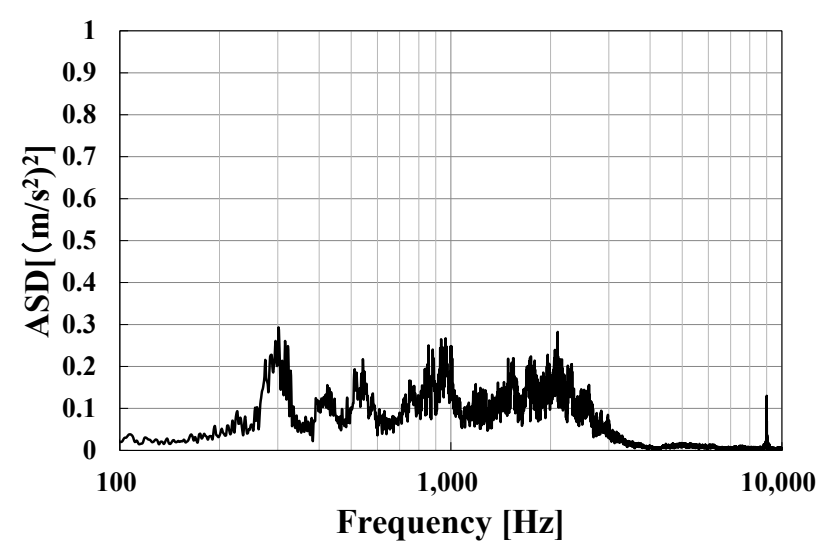

(b) $\alpha=0.7$

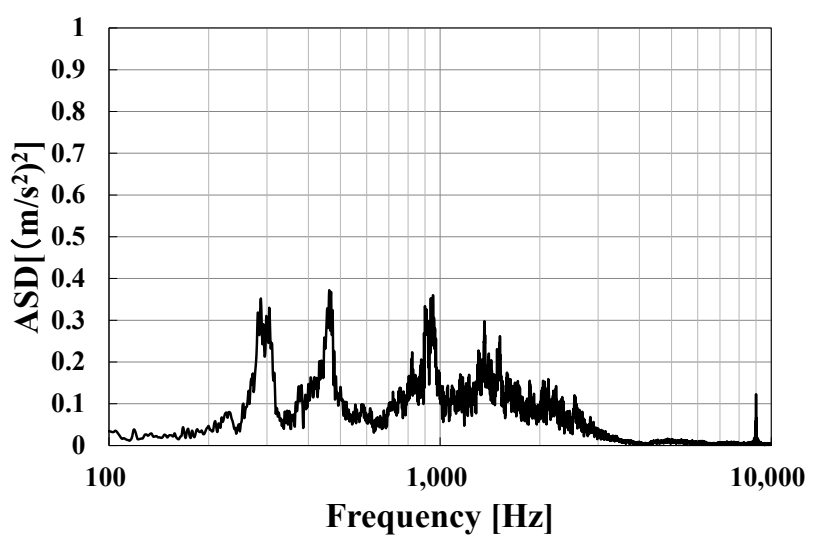

(c) $\alpha=1.0$

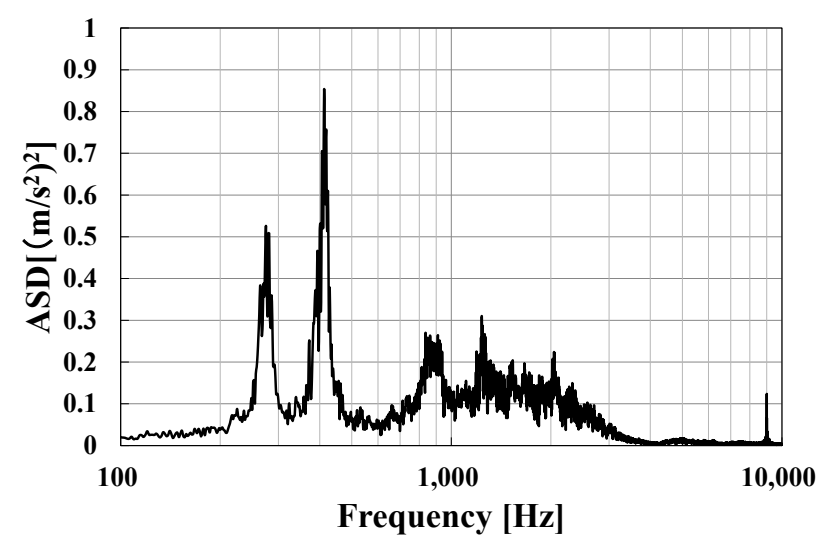

(d) $\alpha=1.4$

Figure 10. Acceleration spectrum density of Z-axis of spindle

\section{Summary}

A machine tool was constructed with a novel counter-balance mechanism on the spindle driving the Z-axis and investigated a model to estimate the appropriate balance mass for the step-drilling process.

1. It was found that we could predict natural frequency exactly by modelling the ball screw transport, and investigate the frequency response function.

2. The vibration of the fixed table could largely be decreased in ball screw transport by making the counterweight weigh the same as the spindle.

3. The influence on the natural frequency of the ball screw transport of the counterweight varied according to the patterns of movement. Therefore, it was necessary to investigate torsion and axial vibration in detail when the weight was set for the counterweight.

\section{Acknowledgements}

This work was supported in part by a grant of Mitutoyo Association for science and Technology.

\section{REFERENCES}

[1] H. Watanabe, H. Tsuzaka, M. Masuda, "Microdrilling for printed circuit boards (PCBs) - Influence of radial run-out of microdrills on hole quality", Precision Engineering, Vol. 32, (2008), pp. 329-335.

[2] T. Hirogaki, E. Aoyama, K. Ogawa, T. Otsuka, H. Nojiri, "Study on Thermal Damage of Micro Diameter Hole Drilled by Super-High-Speed Spindle in PWB and Optimum Drilling Condition", Transactions of the Japan Society of Mechanical Engineers, Vol. 74, No. 743 (2008), pp. 1894-1900.

[3] R. Venkatraman, K. Ramakrishna, K. Knadle, W. T. Chen, G. C. Haddon, "Evaluation of Smear and Its Effect on the Mechanical Integrity of Plated Through Hole-Inner Plane Interface in Thick Printed Wiring Boards", ASME, Journal of Electron Package, 123, MARCH (2001), pp.6-15.

[4] E. Aoyama, T. Hirogaki, K. Ogawa, S. Nojiri, Y. Takeda, "Effect of Rapid-Feed Step-Drilling Cycle and Super-High-Speed Spindle for High-Speed Micro Drilling in Printed Wiring Boards", Trans Tech Publications, Key Engineering Materials, 447-448, (2010), pp.836-840. (in Japanese)

[5] A. Matsubara, "Design and Control of Precision Positioning and Feed Drive systems", No.1(2008), pp.123-140. 